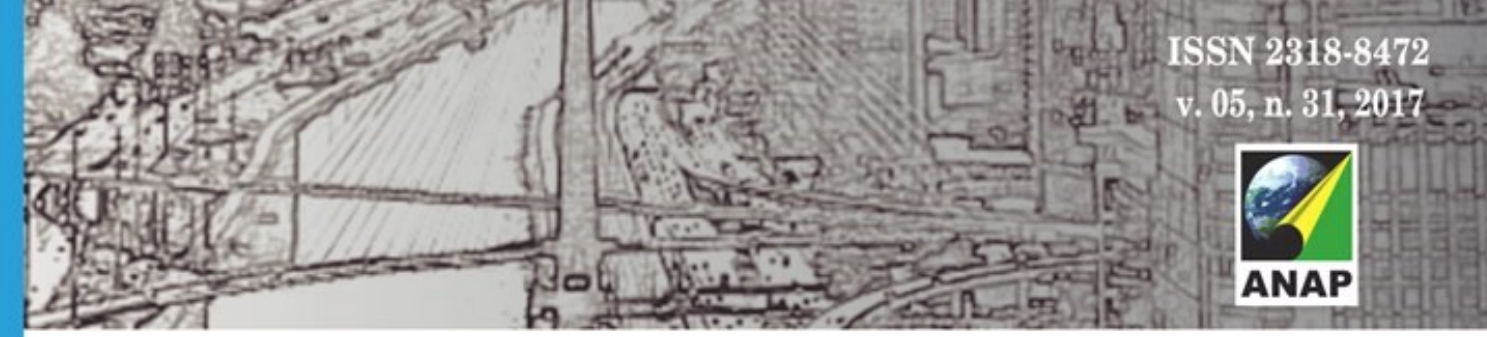

\title{
Espaços Públicos e suas Implicações: Um estudo sobre a cidade de Teresina/PI
}

Public Spaces and their Implications: A study on the city of Teresina / PI

Espacios Públicos y sus implicaciones: Un estudio sobre la ciudad de Teresina / PI

Emanuelle de Aragão Arrais

Graduanda em Arquitetura e Urbanismo, UNINOVAFAPI, Brasil

emanuelle aragao arrais@hotmail.com

Ana Cristina Claudino de Melo

Professora do Departamento de Arquitetura e Urbanismo, UNINOVAFAPI, Brasil acm.arq@hotmail.com

Ana Virgínia Alvarenga Andrade Professora do Departamento de Arquitetura e Urbanismo, UNINOVAFAPI, Brasil anavirginia@uninovafapi.edu.br 


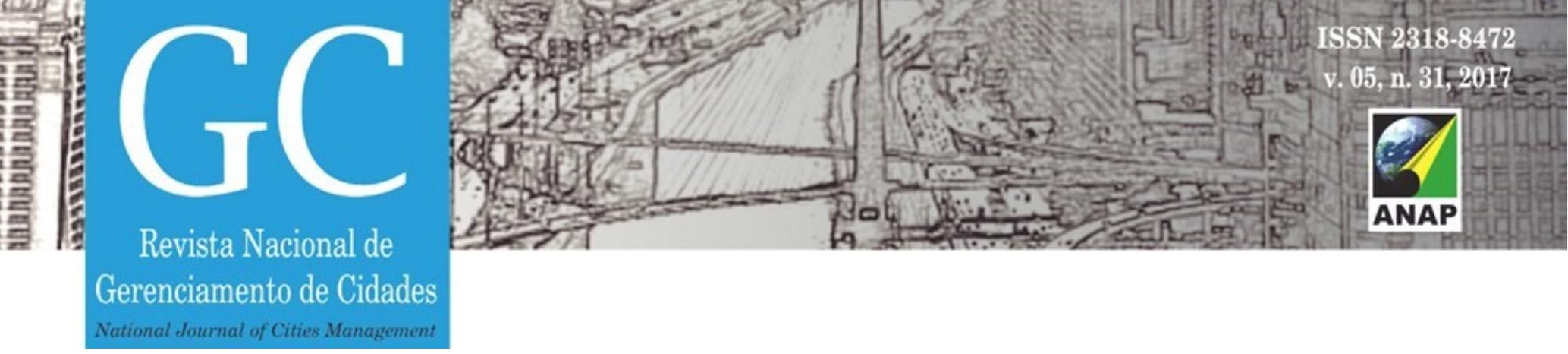

RESUMO

A cidade é o lugar dos seres humanos. É nesse lugar que encontramos vivendo hoje a maioria das pessoas. É nas cidades que temos as maiores alterações na paisagem, e essas alterações geralmente comprometem a qualidade de vida. A supressão do verde das plantas é uma característica marcante nesse espaço. $O$ presente trabalho procura pesquisar sobre a urbanização, os espaços livres e suas implicações na atualidade. Tem como objetivo a investigação das características urbanas de Teresina, juntamente com a análise de seus espaços livres. Isso se desenvolve a fim de examinar como se dá a influência das variáveis teóricas, na realidade do uso das praças nos espaços públicos de Teresina. Esta pesquisa está dividida e etapas distintas. Durante o trabalho foram discutidos sobre a urbanização brasileira, a urbanização de Teresina, e seus espaços públicos. A pesquisa mostrou que há uma necessidade dos espaços livres públicos que passa a ser observada também pela importância de suas características socioculturais e pela relação que estes espaços estabelecem com outros sistemas urbanos. Também é importante salientar sobre os diversos usos e funções das praças na malha urbana.

PALAVRAS-CHAVE: Urbanização; Espaços Livre; Teresina/PI; Praças

\section{ABSTRACT}

The city is the place of human beings. It is in this place that we find most people living today. It's in the cities that have the biggest landscape changes, and these changes usually compromise the quality of life. The abolition of the green of the plants is a striking feature in this space. This paper seeks to research the urbanization, the open spaces and its implications today. Aims research urban characteristics of Teresina, along with the analysis of your spaces. It develops in order to examine how the influence of theoretical variables, in fact the use of squares in the public spaces of Teresina. This research is divided into discrete steps. During the study were discussed about the brazilian urbanization, the urbanization of Teresina, and their public spaces. Research has shown that there is a need of free public spaces which happens to be observed also for the importance of their socio-cultural characteristics and the relation that these spaces with other urban systems. It is also important to note about the various uses and functions of the urban fabric squares.

Keywords: Urbanization; Free Spaces; Teresina; Squares

\section{RESUMEN}

La ciudad es el lugar de los seres humanos. Es en ese lugar donde encontramos hoy la mayoría de las personas. Es en las ciudades que tenemos las mayores alteraciones en el paisaje, y esas alteraciones generalmente comprometen la calidad de vida. La supresión del verde de las plantas es una característica marcada en ese espacio. El presente trabajo busca investigar sobre la urbanización, los espacios libres y sus implicaciones en la actualidad. Tiene como objetivo la investigación de las características urbanas de Teresina, junto con el análisis de sus espacios libres. Esto se desarrolla a fin de examinar cómo se da la influencia de las variables teóricas, en la realidad del uso de las plazas en los espacios públicos de Teresina. Esta investigación está dividida y etapas distintas. Durante el trabajo se discutieron sobre la urbanización brasileña, la urbanización de Teresina, y sus espacios públicos. La investigación mostró que hay una necesidad de los espacios libres públicos que pasa a ser observada también por la importancia de sus características socioculturales y por la relación que estos espacios establecen con otros sistemas urbanos. También es importante subrayar sobre los diversos usos y funciones de las plazas en la malla urbana.

Palabras clave: Urbanización; Espacios libres; Teresina; Plazas 


\section{INTRODUÇÃO}

"Não se pode chamar de cidade um lugar onde não existam praças e edifícios públicos. " (PAUSÂNIAS apud SITTE, 1992).

A praça é constituída a partir da história que ela carrega, do seu desenho paisagístico e do seu conjunto urbanístico. A associação entre morfologia, estética e apoderamento é o que permite a formação de praças, como espaços simbólicos, lugares de memória, se tornando a alma da cidade. É desse modo que podemos entender a frase acima, visto que, na Antiguidade, as cidades formavam-se a partir dos seus espaços de convivência. Ser cidadão, era ocupar os lugares de reunião, era compartilhar o culto, participar das assembleias, assistir às festas, acompanhar as procissões, vivenciar os espaços, participando ativamente da vida pública. A praça simbolizava a própria cidade, pois era nesse espaço que as atividades cotidianas se desenvolviam (COULANGES,1975).

Na Antiguidade clássica, a praça era o espaço público de maior importância da cidade e funcionava como seu centro. Materializada na figura da Ágora ou do Fórum, a praça, com seu conjunto arquitetônico, executava um papel fundamental: era o locus publicci da vida citadina. Neste espaço o conceito de civitas se fazia presente.

Marcus Vitruvius, arquiteto romano do primeiro século, ao descrever os parâmetros de formação da cidade em sua obra De Architectura Libri Decem (Livro I, VII), salienta a relevância da constituição de espaços de uso coletivo na formação das cidades. Descreve também a necessidade de existência de uma praça, situada em posição de destaque e conformada pelos principais edifícios institucionais. (VITRUVIUS,1960)

Com seus diversos significados - funcionais ou morfológicos - a praça simbolizava o espaço de maior vitalidade urbana. Eram espaços referenciais, atuando como marcos visuais e como pontos focais na organização da cidade. (ZUCKER,1959). Esse status alcançado pela praça se faz presente no imaginário urbano. Apesar de que apresentem transformações significativas, as praças representam verdadeiros nós de concentração social e são essenciais ao cotidiano da cidade.

Como elemento urbano, as praças representam espaços de sociabilidade propícios ao encontro e ao convívio. Na cultura ocidental, esses espaços têm desenvolvido um papel essencial. Toda cidade possui uma praça que se destaca como símbolo urbano, palco de eventos históricos, espaço agregador, ou local de confluência. As praças são espaços permanentes no desenvolvimento das cidades. Sua função e morfologia, porém, estão atreladas aos processos de formação política, social e econômica próprios da gênese urbana. (KOSTOF,1992)

Deste modo, as praças marcam a estrutura das cidades. Divergem de outros espaços por constituírem vazios na malha urbana. Incorporadas a conjuntos arquitetônicos, funcionam como pontos de limitação ao proporcionar uma ruptura na paisagem circundada pelas edificações. Praças como a Praça Tiradentes, de Ouro Preto, a Praça XV, no Rio de Janeiro ou a 


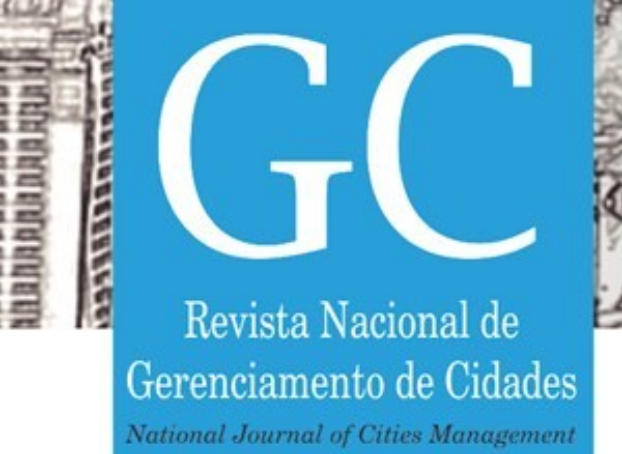

produtividade das riquezas nacionais. Três produtos merecem destaques no processo de exploração e formação do estado brasileiro, são eles: o pau-brasil, a cana-de-açúcar e o café.

Santos (2008), em seu livro sobre a urbanização brasileira diz que durante séculos o Brasil como um todo é um país agrário e cita a célebre expressão do conde Afonso Celso, que nos considerava um país "essencialmente agrícola".

No final do século XIX o Brasil passa por transformações que promovem a mudança dos processos capitalistas do campo para a cidade. Por volta de 1929, com a quebra da bolsa de valores de Nova York, ocorreu uma crise na economia cafeeira. Intensificou-se o êxodo rural, provocando aumento significativo da população urbana. Esse contingente humano passa a ser operário nas indústrias e tornam-se consumidores dos produtos industrializados nos centros urbanos.

As principais cidades transformaram-se em polos de atração para a
população do território, especialmente a que vivia no campo. Nesse
contexto, essa população observava a cidade com uma nova
perspectiva do trabalho, da melhor remuneração, do acesso aos
serviços, a exemplo da saúde e da educação, enfim, a melhoria da
sua qualidade de vida. (VIANA, 2007)

A urbanização brasileira apresentou um ritmo bastante acelerado durante a segunda metade do século $X X$, período em que a indústria teve um grande avanço no país. No decorrer deste século, o Brasil deixa de ser um país rural de atividade primária e passa a ser urbano e industrial.

Entre 1940 e 1980, dá-se verdadeira inversão quanto ao lugar de residência da população brasileira. Há meio século atrás (1940), a taxa de urbanização era de 26,35\%, em 1980 alcança 68,86\%. Nesses quarenta anos, triplica a população total do Brasil, ao passo que a população urbana se multiplica por sete vezes e meia. Hoje, a população urbana brasileira passa dos $77 \%$, ficando quase igual à população total de 1980. (SANTOS, 2008)

A industrialização por si só não explica a evolução do processo de urbanização do Brasil. Pode-se considerar que além das forças de atração existiram também as forças de repulsão, como: as péssimas condições de vida no campo e a modernização da produção agrícola.

Uma característica comumente encontrada no processo de urbanização das cidades brasileiras é que esse fenômeno acontece de maneira rápida e sem uma política de 


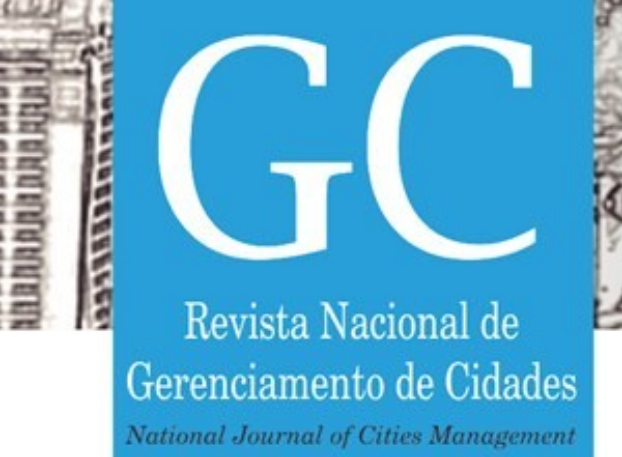

uso do solo urbano adequada, que possa definir a melhor maneira de se utilizar o solo da cidade. Com isso tem-se um aumento do número de vilas e favelas construídas muitas vezes em locais totalmente inapropriados para habitações humanas.

Esse tipo de crescimento do espaço urbano que não apresenta uma política de uso correto do solo, acabando por agravar ainda mais outros problemas encontrados nas cidades, como o aumento do índice de doenças, deslizamentos de barreiras, alagamentos, poluição e até óbitos, uma vez que, os lugares onde boa parte da população constrói suas casas são lugares de risco.

O descontrole processual em que se dá o uso do solo produz dificuldades técnicas de implantação de infraestrutura, altos custos de urbanização e desconforto ambiental de várias ordens (térmico, acústico, visual, de circulação). E a contaminação ambiental resultante implica um lugar desagradável para viver e trabalhar. (LOMBARDO, 1985)

Para Loboda e DeAngelis (2005), as cidades brasileiras estão passando por um período de intensa urbanização, fato que reflete-se de forma negativa na qualidade de vida de seus moradores. Associado à crescente urbanização brasileira, temos a falta de um planejamento que considere as condições naturais de cada região brasileira.

São inúmeros e de diferentes amplitudes os problemas que podem ocorrer em virtude de não se considerar as características naturais durante as atividades e projetos de planejamento nas cidades.

A concentração urbana brasileira já ultrapassa a ordem de $80 \%$ da população, e o seu desenvolvimento tem sido realizado de forma pouco planejada, sendo que um dos principais problemas relacionados com a ocupação urbana desordenada são os impactos socioambientais. Sendo a urbanização uma transformação da sociedade, os impactos ambientais promovidos pelas aglomerações urbanas são, ao mesmo tempo, produto e processo de transformações dinâmicas e recíprocas da natureza e da sociedade estruturada em classes sociais. (VIANA, 2007)

Lombardo (1985) em seu estudo sobre ilha de calor nas metrópoles afirma a concentração demográfica nas grandes cidades se distribui de maneira caótica, gerando um ambiente de contradições sociais que se reflete na desorganização territorial, somando-se as modificações produzidas no ambiente. Nesse contexto o 


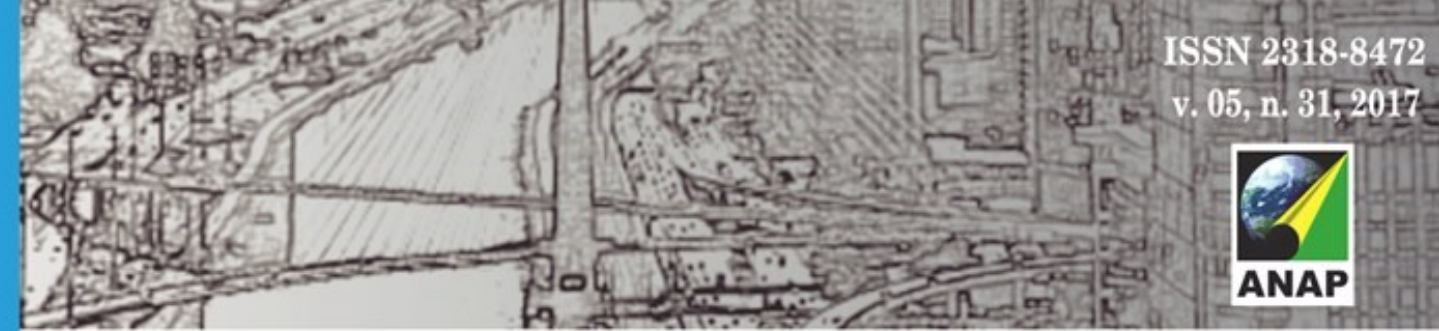

Gerenciamento de Cidades

processo acelerado de urbanização do Brasil pode ser apontado como uma das principais causas.

Com diferença de grau de intensidade, todas as cidades brasileiras exibem problemáticas parecidas. Seu tamanho, tipo de atividade, região em que se inserem etc. são elementos de diferenciação, mas, em todas elas, problemas como os do emprego, da habitação, dos transportes, do lazer, da água, dos esgotos, da educação e saúde são genéricos e revelam enormes carências. Quanto maior a cidade, mais visíveis se tornam as mazelas. (SANTOS, 2008)

Os diversos problemas e desafios atuais enfrentados nas cidades brasileiras têm demonstrado que se faz necessário um estudo e uma política séria de planejamento urbano, que considere a população e a economia, mas sem relegar a dependência que temos da natureza.

A urbanização crescente da humanidade, mesmo a latino-americana e mais especificamente a brasileira, cujo fenômeno de metropolização aparece como efeito mais intenso, tem preocupado aqueles que se relacionam profissionalmente com a questão do meio ambiente (LOMBARDO, 1985)

Durante o processo de crescimento das cidades brasileiras tem-se observado uma expansão dos espaços construídos, sem se considerar a devida atenção às questões ambientais, que representam uma etapa fundamental quando se considera um país de imenso território como é o caso do Brasil, onde cada estado e cidade apresentam características naturais particulares.

\section{ESPAÇOS PÚBLICOS E SUAS IMPLICAÇÕES}

\section{Contextualização}

A realidade das cidades brasileiras contemporâneas tem apresentado um crescimento disperso e espraiamento, provocada em sua maioria pela disponibilidade e baixo valor da terra (SANTOS, 1993). Essas condições exigem maiores percursos nos deslocamentos diários da população, restringem as possibilidades de deslocamentos a pé e consequentemente reduzem a interação do pedestre com o espaço público. Apesar desse contínuo processo de restrição que se impõe aos pedestres, no Brasil cerca de $30 \%$ das viagens cotidianas da população brasileira são realizadas a pé (IBGE, 2010). Portanto, é um modal que tem relevância nas vidas das pessoas e está intrinsicamente relacionado com o uso dos espaços públicos. 


\section{O objetivo do desenho urbano como atributo do espaço}

O esvaziamento dos espaços públicos em horários específicos ou durante todo o dia, segundo alguns autores, pode ser resultado da uniformidade de tipos de uso oferecidos. Bentley et al (1997) defendem a variedade, com a oferta de usos e atividades instaladas, como meio de atrair públicos diferentes em horários distintos. Abordada por Jacobs (1961), a diversidade de uso é tratada como uma necessidade das praças e parques, visto que estimulam os usuários a circularem e o espaço torna-se ativo o dia inteiro, pois a presença de pessoas atrai outras pessoas.

A variedade de usos dos edifícios propicia ao parque uma variedade de usuários que nele entram e dele saem em horários diferentes. Eles utilizam o parque em horários diferentes porque seus compromissos diários são diferentes. (JACOBS, 2001)

O Urban Design Compendium (UDC) cita vários benefícios da mistura de usos e formas para o espaço público, como o fácil acesso às instalações por meio da caminhada, redução de congestionamentos, maior interação social, maior sensação de segurança, entre outros. O By Design também identifica vantagens na mistura de usos, que pode ocorrer na escala do edifício (um uso sobre o outro), na rua (um uso próximo ao outro), ou na vizinhança (grupo de usos próximos), de modo que o equilíbrio reduza a dependência em relação ao carro. Observa-se que, a diversidade de uso não é a geradora de movimento, ela deve estar aliada à malha que permita uma facilidade de movimento, para assim tornar o espaço ativo e reduzir a necessidade de grandes deslocamentos pelos usuários para atender suas necessidades. Para Hillier (1996), a localização de usos comerciais, por exemplo, deve levar em consideração a relação entre a integração da malha e movimento, e contribuir para ampliar e manter a circulação de pessoas.

Para que se permita a facilidade de movimento é necessário que o espaço seja receptivo; Bentley et al (1997) defendem que a permeabilidade é um aspecto que eleva a acessibilidade, pois permite um maior número de opções disponíveis para ir de um ponto a outro. A disposição de quadras curtas na malha urbana é uma solução para favorecer a permeabilidade nos espaços públicos, pois oferece maiores oportunidade de rotas aos usuários (JACOBS, 1961). Para a vitalidade das praças, isso pode ser 


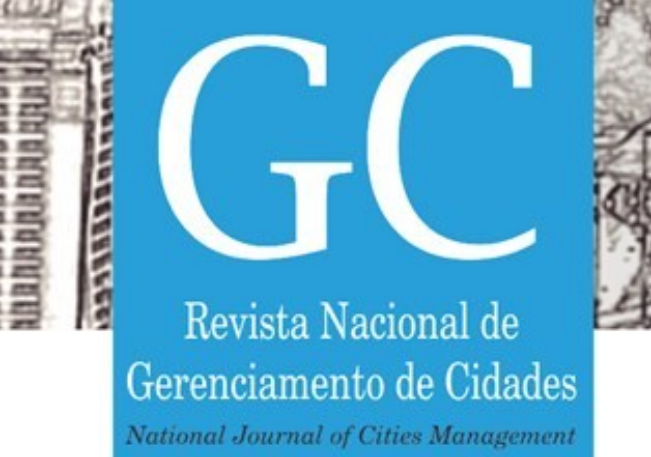

Tabela 1: Relação quantitativa de praças e parques de Teresina. Fonte: LOPES (2011).

\begin{tabular}{lc}
\hline \multicolumn{1}{c}{ SUPERINTENDENCIA } & QUANTIDADE \\
\hline CENTRO-NORTE & \\
PRAÇAS & 109 \\
PARQUES AMBIENTAIS & 14 \\
SUL & \\
PRAÇAS & 102 \\
PARQUES AMBIENTAIS & 12 \\
LESTE & \\
PRAÇAS & 51 \\
PARQUES AMBIENTAIS & 11 \\
SUDESTE & \\
PRAÇAS & 35 \\
PARQUES AMBIENTAIS & 04 \\
\hline Total & $\mathbf{3 3 8}$ \\
\hline
\end{tabular}

\section{OBJETIVOS}

O objetivo deste trabalho é a investigação das características urbanas de Teresina, juntamente com a análise de seus espaços livres. Isso se desenvolve a fim de examinar como se dá a influência das variáveis teóricas, na realidade do uso das praças nos espaços públicos de Teresina.

\section{METODOLOGIA/MÉTOdO DE ANÁLISE}

Pesquisa bibliográfica; sobre aspectos ligados à paisagem, crescimento urbano, espaço, lugar, tipos de espaços livres, público e privado, qualidade ambiental, lazer e recreação, circulação, apropriação e patrimônio cultural, entre outros; $E$ a análise e discussão sobre da distribuição dos espaços nas regiões da cidade considerando área dos espaços livres.

\section{RESULTADOS}

A cidade de Teresina, com área de 1.1672 .5 km², 113 bairros e população de 804.943 habitantes (IBGE, 2010), diferente das outras capitais do Nordeste, está localizada no interior do Estado, não dispondo, dessa forma, do espaço democrático de lazer, representado pelas áreas litorâneas. Apresenta clima tropical, com chuvas no verão, com temperatura anual média de $26,7^{\circ} \mathrm{C}$, podendo atingir nos meses mais quentes, até $40^{\circ} \mathrm{C}$. 


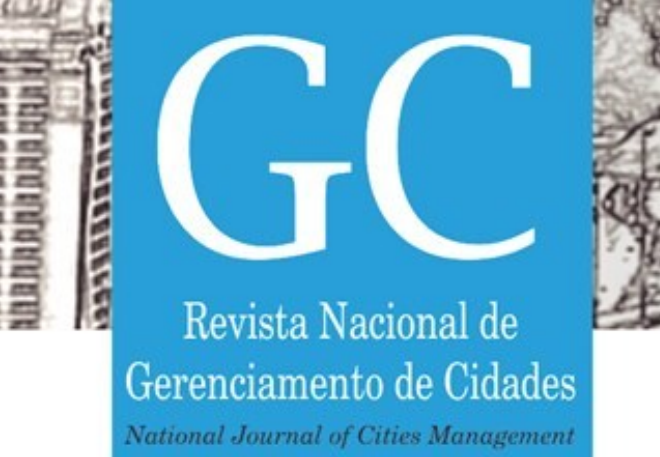

Procura-se comentar neste trabalho, que dentre muitos problemas existentes em Teresina, alguns pontos como o que a cidade ainda não conseguiu resolver na perspectiva do equilíbrio com a natureza tanto no espaço privado quanto no público, preconizado pelas Agendas Internacionais.

\section{AGRADECIMENTO}

Agradeço as minhas orientadoras e ao Departamento de Arquitetura e Urbanismo do Centro Universitário UNINOVAFAPI.

\section{REFERÊNCIAS BIBLIOGRÁFICAS}

BENTLEY, Ian; ALCOCK, Alan; MURRAIN, Paul; MCGLYNN, Sue; SMITH, Graham.

BRANDÃO, Zeca. Urban Planning in Rio de Janeiro: a Critical Review of the Urban Design Practice in the Twentieth Century. City \& Time 2 (2): 4. 2006. Disponível em:

http://courses.arch.ntua.gr/fsr/135685/CT-2006-53-3.pdf . Responsive Environments: A Manual for Designers. Oxford: Architectural Press, 1997.

COULANGES, Fustel. A cidade antiga: estudos sobre o culto, o direito, as instituições da Grécia e de Roma. Trad. José Camargo Leite e Eduardo Fonseca. São Paulo: HEMUS, 1975.

DEL RIO, Vicente. Introdução ao desenho urbano do Processo de Planejamento. São Paulo: Pini, 1990.

GEHL, Jan. La humanización del espacio urbano: la vida social entre los edifícios. Barcelona: Reverté, 2006.

HILLIER, Bill. Space is the machine. Londres: Cambridge University Press, 1996.

HOLANDA, Frederico de. Espaço de Exceção. Brasília: Editora da UNB, 2002.

HOLANDA, Frederico de. Arquitetura \& Urbanidade. São Paulo: pro-editores, 2003.

IBGE. Instituto Brasileiro de Geografia e Estatística. Censo demográfico do Brasil de 2010. Rio de Janeiro.

JACOBS, Jane. Morte e vida de grandes cidades. [1961] Tradução Maria Estela Heider Cavalheiro. São Paulo: Martins Fontes, 2001.

KOSTOF, S. The City Assembled: The elements of Urban Form through History, Bulfinch Press Book Little, Brown and Company, London, 1992.

LAMAS, José Manuel Ressano Garcia. Morfologia Urbana e Desenho da Cidade. 3. Ed. Lisboa: Fundação Calouste Gulbenkiam/Fundação para a Científica e a Tecnologia, 2004.

LOBODA, Carlos Roberto; DE ANGELIS, Bruno Luiz Domingos. Áreas verdes públicas urbanas: conceitos, usos e funções. Ambiência Guarapuava-PR. V.1n.1. p.125-139. 2005. 


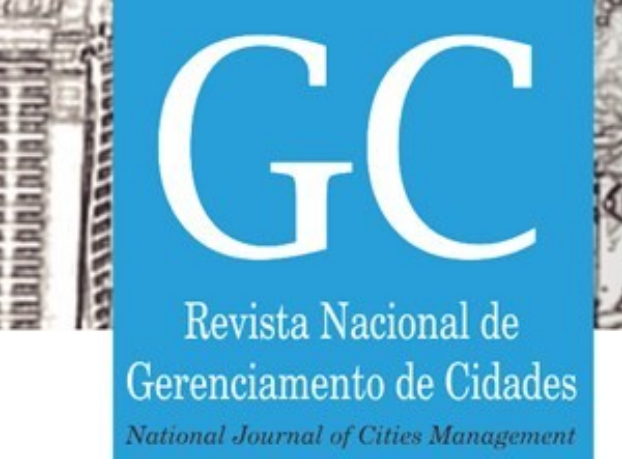

LOMBARDO, M. A. Ilha de calor nas metrópoles: o exemplo de São Paulo. São Paulo: Hucitec, 1985. 224p.

LYNCH, Kevin. A Imagem da Cidade. São Paulo: Martins Fontes, 1980.

ROGERS, Richard; GUMUCHDJIAN, Philip. Cidades para um pequeno planeta. Barcelona: Gustavo Gilli, 1997.

SANTOS, Milton. A urbanização Brasileira. São Paulo: Hucitec, 2008.

SITTE, Camillo. A Construção de Cidades Segundo Princípios Artísticos. Trad. Ricardo Ferreira Henrique. São Paulo: Ática, 1992.

VIANA, Bartira Araújo da S. Mineração de materiais para construção civil em áreas urbanas: impactos socioambientais dessa atividade em Teresina, Pi / Brasil. Dissertação defendida pelo Programa Regional de PósGraduação e Meio Ambiente da Universidade Federal do Piauí (PRODEMA/UFPI/TROPEN), 2007.

VIEIRA, Maria Elena Merege. O jardim e a paisagem: espaço, arte, lugar. São Paulo. Annablume editora, 2007.257 p. VITRUVIUS, Marcus Pollio The Ten Books on Architecture. New York: Dover Publication,1960

WHYTE, William H. The Social Life of Small Urban Spaces. New York: Project for Public Spaces, 2004.

ZUCKER, Paul. Town and Square - from the Ágora to the Village Green. New York: Columbia University Press, 1959:2. 